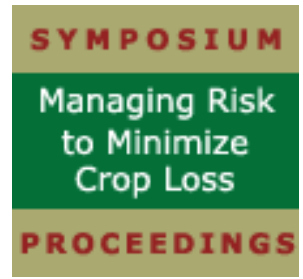

(C) 2003 Plant Management Network.

Accepted for publication 27 March 2003. Published 13 November 2003.

\title{
Risk Assessment: Concepts, Development, and Future Opportunities
}

X. B. Yang, Department of Plant Pathology, 351 Bessey Hall, Iowa State University, Ames 50011-0001

Corresponding author: X. B. Yang. xbyang@iastate.edu

Yang, X. B. 2003. Risk assessment: Concepts, development and future opportunities. Online. Plant Health Progress doi: 10.1094/PHP-2003-1113-02-RV.

Farming is a risky business with many uncertainties that affect its success. Among the many risk factors, plant disease is an important one due to its close relation to climate and yield. Outbreaks of diseases reduce yield and cut profit margins. Improper management of a disease several years in a row could put a producer out of business. Understanding and assessing disease risk reduce the uncertainties and, therefore, are critical to effective management of plant diseases and, ultimately, to the success of the particular farming venture.

\section{Agricultural Trends and Disease Risks}

Several major trends in agriculture shape or affect production systems and impact disease risk at different levels. The first trend is increased movement of plant materials and germplasm among countries and continents in association with global agricultural trade. Increased movement increases the risk of introduction of exotic pathogens. Second, climate changes (2) are associated with emergence and re-emergence of plant diseases and thus changing disease pictures which consist of types, patterns, and intensity of diseases. Climate changes are linked to increased frequency of extreme weather events, which are known to affect disease outbreaks (6). Third, use of genetically modified crops sometimes can significantly change a production system. For example, use of Roundup Ready soybean, a genetically modified soybean resistant to herbicide (glyphosate), reduces the amount of applications of other herbicides that affect soil micro-organisms differently from glyphosate. Use of Roundup Ready soybeans also has advantages in weed management under no-till systems and, therefore, promotes no-tillage practices. Because changes in production systems are often associated with changes in disease pictures, changes after the deployment of genetically modified crops could help manage existing disease problems or might bring new disease concerns for growers. Studies showed that use of Bt corn reduced insect-borne corn ear rot (4). On the other hand, the introduction of Roundup Ready soybeans was followed by farmers' concerns about sudden death syndrome caused by Fusarium solani f. sp. glycines in the US (8). Finally, society's demand for environmentally friendly agricultural production requires a higher standard of disease management such as the use of biological control, which also has risks associated with its use, and these risks must be assessed (13).

Besides the above mentioned trends, another major trend in US agriculture is the increase in farm size and decrease in the number of farms, along with an increase in the aggregation of production. Based on a 1998 report (3), 144,000 farms, accounting for $7 \%$ of farms, produce $75 \%$ of all farm production. The future US farming system is predicted to have only of 150,000 farms. Increase in farm size would likely be associated with a change from disease control to disease prevention. Producers in large production enterprises would have limited time for short-term operations to control disease, such as application of fungicides before imminent disease outbreaks. Management for large-scale production would be more efficient by focusing on disease prevention, with implementations made prior to planting or in the early part of a growing season. To make decisions for pre-season disease management operations, such as variety selection, producers would need information on mid-term (3 to 6 months) to long-term (more than 6 months) disease risk. 
Disease Risk Studies

With current agricultural trends, demand for disease risk information is likely to increase. This information can be placed in two groups: potential impact of new or re-emerging diseases, and prediction of outbreaks of diseases that are current production problems. Accordingly, users of disease risk information are in two groups. The first group, which consists of funding agencies, policy makers, researchers, and industry R\&D managers, needs information for long-term investment. They need risk assessment information on potential new diseases or re-emerging disease problems. The second group consists of people who need risk prediction for decision making to manage potential disease outbreaks, such as farmers, farm advisers, agronomists, and horticulturists in universities or seed and chemical companies who provide production management services to farmers.

A quantitative disease risk study is a two-phase endeavor. The first is the development of a disease risk prediction system and the second is implementation of the system to predict the likelihood of disease occurrence at a specific time in specific locations. In the past, different terminology has been used to describe various disease risk studies, such as disease forecasting, disease prediction, risk assessment, and risk prediction. The term "risk assessment" has been used to define the prediction of likely damaging levels of a disease on various scales, from on-farm disease prediction to regional impact assessment of a new disease. In other words, a risk assessment is aimed at generating information on the likelihood of the occurrence of a disease on specific scales determined by users. A study is called risk assessment when prediction is made for a large scale. Otherwise, disease risk prediction is more appreciated when predictions are for site-specific situations. According to users, risk studies can be grouped as following: (a) risk assessment, which provides risk information for decision making to policy-makers and funding agencies; (b) disease risk prediction, which provides disease forecasting information for people on the production front.

Risk assessment and disease risk prediction are different in scales of study, users of risk information, and feasibility of validation (Table 1). For the latter, prediction often is made at the farm level or at the level of a specific area. For risk assessment, prediction has a spatial scale as large as a country or a continent. In temporal scales, risk assessment addresses questions of future disease problems in years or a decade to come. Disease risk prediction forecasts population dynamics of a plant pathogen in the next few days or weeks in a season. Because risk assessment makes long-term predictions, validation of assessments may not be made for many years in the future.

Table 1. Comparison between disease risk prediction and disease risk assessment for subject matter, users, and scale of study.

\begin{tabular}{|l|l|l|}
\hline & Disease risk prediction & Disease risk assessment \\
\hline Subject & population & agroecosystem \\
\hline Time & day or season & years to decade(s) \\
\hline Space & field or area & region or continent \\
\hline Users & production front & decision table \\
\hline Validation & yes & uncommon \\
\hline
\end{tabular}

There are also differences in methodology between risk assessment and disease risk prediction as the latter is better developed. Disease risk prediction utilizes both disciplines of epidemiology and meteorology. Risk assessment is developed from the sciences of epidemiology and climatology, with additional concepts and methodologies from environmental science. In risk assessment, epidemiology is the core subject area, with additional concepts that are rooted in disease loss assessment and environmental science. For example, the procedure for an early framework of risk assessment proposed by Teng and Yang (14) was similar in assessment to the risk assessment procedure used by environmental scientists. Generally, the framework for disease risk assessment can be simplified to a five-step process (Fig. 1): risk determination, data and 
information collection, system synthesis, prediction of risk probability, and risk interpretation and communication. Unlike disease risk prediction, risk assessment does not have validation as a critical step in its framework because large-scale historical data is scarce for validation.

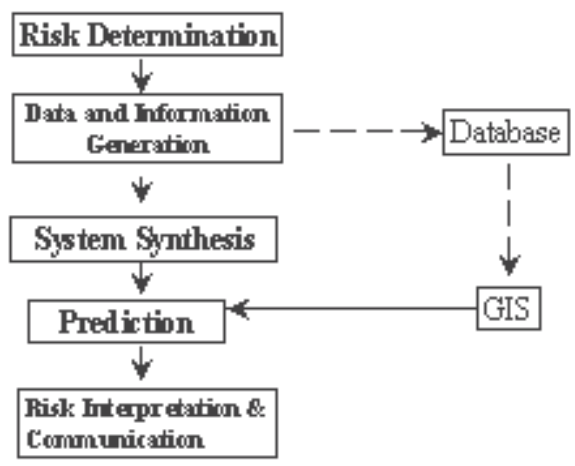

Fig. 1. Process of disease risk assessment.

Disease risk prediction is to forecast the likelihood of disease outbreaks in a production situation. Studies in this area are commonly called disease forecasting by many epidemiologists. This area is more advanced than risk assessment and prediction of disease outbreaks has been an ultimate goal of many epidemiological projects. Numerous reviews are available on this topic and we will not discuss it further.

\section{Gaps in Risk Assessment}

Before 1990, risk assessment related studies were mainly with exotic diseases focusing on establishment of quarantine subjects. Assessments were made using qualitative approaches where expert opinions together with geophytopathological information were synthesized. In the past ten years, advances have been made in quantitative risk assessment following the rapid development of computation and database technology. Various studies have been conducted to assess the risk of emerging disease (10) and exotic diseases, their likelihood of establishment, and potential impact on yield $(14,15)$.

Despite recent advances, risk assessment is still more an art than a science, which is evident by the lack of standard methodology and framework for assessment. Often, information/ data gaps exist in a disease risk assessment study, especially for a disease that has not been thoroughly studied. Consequently, arbitrary elements, such as an expert's experience, are integrated into the assessment, resulting in potential bias. Two major gaps in the development of risk assessment are the lack of studies in (a) macro-scale patterns of disease occurrence, and (b) assessment validation.

Macro-scale patterns. As mentioned before, a disease risk assessment studies the potential occurrence of a disease in a large region. Occurrence of a disease at such a scale should be affected by the climate patterns in the assessed region and follow the spatial patterns (dispersal and distribution) of its causal agent. Interactions between climate patterns and pathogen spatial patterns should produce the large-scale patterns of disease occurrence in time and space, information which is lacking. In disease risk assessment, the most needed information in terms of occurrence of a disease is: (i) areas identified in a region or country that are favorable or unfavorable to the disease; and (ii) frequencies of disease epidemics in regions favorable to the disease once the pathogen is established. Theoretically, predictions of disease distribution and periodical occurrence can be made by linking pathogen biological parameters to climatic databases.

Recent studies show that the occurrence of some diseases within a large time frame may follow certain statistical patterns. Cyclic patterns of disease epidemics have been reported in wheat rusts $(9,17)$. The recent re-emergence of some diseases, such as wheat scab and soybean Sclerotinia stem rot in the northcentral region of the United States, also indicates the possibility of cyclic patterns of these diseases. Long-term dynamics of diseases are associated with climatological events, which affect biological events of a plant pathogen. If 
relationships between response of an assessed disease and climate dynamics are developed, one could use the relationships to predict the periodicity of the disease using long-term climatological data as driving variables in computer models.

In an agroecosystem, large-scale spatial patterns (distribution and dispersal) of a pathogen are likely to determine the regional disease occurrence pattern of the pathogen. Few studies are available on large-scale patterns of pathogen distribution and dispersal because quantifying a pathogen in a large geographical region requires large resources, which are difficult to obtain in epidemiological studies. Further, measurements of a pathogen are likely to be indirect by observing visual disease expression, which is affected by environmental conditions. However, cumulative literature on regional occurrence of diseases is available and analysis of the literature could provide insight on the patterns of large-scale disease occurrence. Using this approach, Yang and Feng (16) recently quantified the distribution range of individual soybean diseases in North America and examined the south-to-north distribution pattern of individual diseases. They reported a statistically significant relationship between disease distribution range and its centeriol, which is the geographic center point of south-north distribution of the disease. Their study suggests that in North America, the distribution range of a soybean disease is a function of pathogen biology and climate. If one could link largescale distribution of a disease to the biological parameters of the pathogen, it may be possible to predict the occurrence and distribution of a disease in a region by using an approach that combines laboratory or greenhouse experiments with statistical predictions.

Validation. In the 1980s, validation of disease prediction models was intensively discussed in the development of disease forecasting. Validation now is a critical step in the development of disease forecasting models. However, validation of risk assessment on a new or re-emerging disease is limited. Often resources are not available to collect data on large spatial scales for validation of predicted distributions. Even with sufficient resources, the long-term dynamics of disease systems at regional and continental scales make immediate validation of an assessment on a new disease unlikely. Some disease risk assessment studies could not be published in traditional journals because of lack of validations. For a risk assessment study, the practical value of the assessment may be realized by users before validation is available. The scientific significance of a study, however, would not be recognized by many until validation is made, even if years later.

Risk assessment of soybean sudden death syndrome caused by Fusarium solani f. sp. glycines is an example of emerging disease assessment. The disease was first reported in Arkansas in the early 1970s and caused production problems endemically in southern states (7). In 1993 the disease was found in Iowa, a leading soybean production state. The soybean industry needed to know the level of the threat of this disease to the north-central region, which produces $78 \%$ of US soybeans, so that the funding agencies could prioritize investment of research funds. The information was also critical to soybean breeders to determine breeding priorities.

A risk assessment for SDS was conducted using Climex, a computer software developed by CSIRO (11), with disease parameters generated from experiments conducted in controlled conditions (10). The projection was that the disease would cause more losses in the north-central region than in the southern region where the disease originated. The study was presented in a 1995 conference and immediately gained soybean industry attention. Breeding for resistance to SDS started before the disease became a production problem in the north-central region. Funding agencies have provided over $\$ 5$ million to university scientists for research to manage this disease and now many seed companies have resistant varieties available to growers. The assessment was not validated until 6 years later. Now the disease has spread to Canada and Minnesota. In the 2000 and 2001 growing seasons, surveys by Southern Illinois University (Myers et al., unpublished) showed the disease was found in over $30 \%$ of soybean fields in central and northern Illinois. Without this risk assessment which promoted resistance breeding and management research, current disease prevalence and epidemics would probably be higher. 
Gaps in Disease Risk Prediction.

The first gap in disease risk prediction is in risk communication. Despite the fact that many reliable disease forecasting models have been developed by epidemiologists, few of them are adopted by producers in their farming practices. One possible reason may be the gap in communicating risk prediction to producers. Most disease prediction models/ systems provide disease forecasting results that are difficult for producers to interpret in relation to their production. Knowledge of how to provide producers with an understanding of risk and the selectionof follow-up management procedures may be a key in risk communication. Use of "risk assessment" instead of "disease prediction" in many web sites hosting disease forecasting models indicates an improvement in disease risk communication.

Another gap is to link disease risk predication across scales for one disease or within one pathosystem. At the current stage of development, disease forecasting models are mainly developed for short-term predictions, information useful to guide chemical controls. In a production system, which emphasizes disease prevention, users of disease risk information are at different decision levels and most of the current predictions cannot meet the needs of many other users. For example, users of disease risk information on soybean Sclerotinia stem rot (caused by Sclerotinia sclerotiorum) include producers, private farm advisers, university extension personnel, funding agencies, and industry mangers (Table 2). Different users need disease risk information on different spatial and temporal scales.

Table 2. Comparison of purpose and scales of risk information among different users of risk information for Sclerotinia stem rot of soybean, caused by Sclerotinia sclerotiorum, in the north-central region of the United States.

\begin{tabular}{|l|l|l|l|}
\hline User & Purpose & Temporal scale & Spatial scale \\
\hline \multirow{4}{*}{ Farmers } & chemical control & in-season & fields/farm \\
\cline { 2 - 4 } & variety selection & coming season & fields/farm \\
\cline { 2 - 4 } & tillage & coming season & fields/farm \\
\hline \multirow{2}{*}{$\begin{array}{l}\text { Extension } \\
\text { agronomists }\end{array}$} & advice & in-season & fields/area \\
\cline { 2 - 4 } & & coming season & fields/area \\
\hline \multirow{2}{*}{$\begin{array}{l}\text { Seed/chemical } \\
\text { companies }\end{array}$} & marketing strategies & next year & regional \\
\cline { 2 - 4 } & breeding decisions & next few years & regional \\
\cline { 2 - 4 } & product development & years/decade(s) & regional \\
\hline Government & funding decision & years & regional \\
\hline
\end{tabular}

Risk of Sclerotinia stem rot of soybean can be managed by utilizing management practices with different time frames. Outbreaks of the disease can be prevented by applying fungicide during flowering, which requires prediction of disease on-set. Risk of the disease in the coming season can be reduced with the use of selected tillage practices and selection of tolerant varieties, operations that are made a few months before a season starts. Because the disease can be managed with resistant varieties, tillage, and fungicides, producers need risk information not only for chemical sprays but also for variety selection and tillage operations a few months before planting. Pre-season risk prediction would be helpful in decision making for these production practices. On the production front, mid-term ( 2 to 4 month lead time) risk prediction is needed and should be possible for many pathosystems. A mid-term disease risk prediction system has been developed for Stewart's wilt on corn, caused by Pantoea stewartii, and was successfully applied. In 2000, a mid-term prediction given a 2-month lead-time was issued successfully (1).

In the much longer term, seed and chemical companies need risk assessment for the development of resistant varieties or chemical products. Since such development takes years or a decade and huge capital investments, assessment of the long-term trends of a disease is critical for investment return. These longterm trends may exist and be identifiable. In wheat strip rust, caused by Puccinia striiformis, a cyclic disease pattern of 4 years was identified in a 
Chinese pandemic region (17), and a possible 8-year cyclic pattern has been suggested (9). A simulation study of the annual occurrence of soybean Sclerotinia stem rot in Iowa using climatic data since 1880 identified a possible 20-year cycle (Mila and Yang, and Li and Yang, unpublished). There were three calculated severe outbreaks which were correlated with recorded epidemics in 1947-1951, 1971-1973 and 1992-1995. During these periods, epidemics of Sclerotinia were reported. The first outbreak corresponds to a time when the disease was first reported in the US. The years for the second peak correlate to a time of widespread Sclerotinia diseases and the first report of Sclerotinia blight of peanut in 1974 in the US (5). Four years later, the first symposium on Sclerotinia diseases was organized at the American Phytopathological Society's annual meeting. The last period was a recent outbreak of this disease in the north-central US. The results indicate that epidemics of the disease may have a 20-year cycle, coincident with a 19-year dry/ wet cycle in the north-central US (12). If this simulation is true, this disease could re-emerge as a production problem every 20 years. Similar studies with other pathosystems should benefit long-term risk assessment and disease management significantly.

\section{Literature Cited}

1. Esker, P., and Nutter, F. W., Jr. 2000. Severe risk for Stewart's disease. Online. Integrated Crop Management Newsletter. IC-484(7): May 1, 2000. Iowa State University Extension.

2. IPCC. 2001. Agriculture in a changing climate: Impacts and adaptation. Pages 427467 in: Climate Change 1995. Impacts, Adaptations and Mitigation of Climate Change: Scientific-Technical Analyses. R. T. Watson, M. C. Zinyowera, and R. H. Moss, eds. Cambridge University Press. Cambridge.

3. Kent, K. 1998. Ag megatrends on horizon. Iowa Farmer Today. April 18, 1998.

4. Munkvold, G. P., and Hellmich, R. L. 2000. Genetically modified, insect resistant maize: Implications for management of ear and stalk diseases. Online. Plant Health Progress doi:10.1094/PHP-2000-0912-01-RV.

5. Purdy, L. H. 1979. Sclerotinia sclerotiorun: History, diseases and symptomology, host range, geographic distribution, and impact. Phytopathology 69:875-880.

6. Rosenzweig, C., Iglesias, A., Yang, X. B., Epstein, P. R., and Chivian, E. 2001. Climate changes and U.S. agriculture: The impacts of warming and extreme weather events on productivity, plant diseases, and pests. Global Change and Human Health 2:90-103.

7. Roy, K. W., Rupe, J . C., Hershman, D. E., and Abney, T. S. 1997. Sudden death syndrome of soybean. Plant Dis. 81:1100-1111.

8. Sanogo, S., Yang, X. B., and Scherm, H. 2000. Effects of herbicides on Fusarium solani f. sp. glycines and development of sudden death syndrome in glyphosatetolerant soybean. Phytopathology 90:57-66.

9. Scherm, H., and Yang, X. B. 1995. Interannual variations in wheat rust development in China and the United States in relation to the El Nino/ Southern Oscillation. Phytopathology 85:970-976.

10. Scherm, H., and Yang, X. B. 1999. Risk assessment for sudden death syndrome of soybean in the north-central United States. Agric. Systems 59:301-310.

11. Sutherst, R. W., and Maywald, G. F. 1991. Climate modeling and pest establishment. Plant Prot. Quar. 6:3-7.

12. Taylor, L.E., 2001. Lesson 2b, Climate Effects On Crops: 20-year cycle. Online. Agronomy 508: Climate and Crop Growth. Department of Agronomy, Iowa State University.

13. TeBeest, D. O., Yang, X. B., and Cisar, C. R. 1992. The status of biological control of weeds with fungal pathogens. Annu. Rev. of Phytopathol. 30:637-657.

14. Teng, P. S., and Yang, X. B. 1993. Biological impact and risk assessment in plant pathology. Annu. Rev. of Phytopathol. 31:495-521.

15. Yang, X. B., Dowler, W. M., and Royer, M. H. 1991. Assessing the risk and potential impact of an exotic plant disease. Plant Dis. 75:976-982.

16. Yang, X. B., and Feng, F. 2001. Ranges and Diversity of Soybean Fungal Diseases in North America. Phytopathology 91:769-775.

17. Yang, X. B., and Zeng, S. M. 1992. Detecting patterns of wheat stripe rust pandemics in time and space. Phytopathology 82:571-576. 